\title{
Impact of marginalization on tobacco use in individuals diagnosed with head and neck Cancer
}

\author{
Grace Margaret Scott ${ }^{1}$, Corliss Best ${ }^{2}$, Kevin Fung ${ }^{3}$, Michael Gupta ${ }^{4}$, Doron D. Sommer ${ }^{4}$, Christopher Szeto ${ }^{5}$ and \\ Damian Christopher Micomonaco ${ }^{5}$
}

\begin{abstract}
Background: Considerable evidence now indicates that individuals living in underprivileged neighbourhoods have higher rates of mortality and morbidity independent of individual-level characteristics. This study explored the impact of geographical marginalization on smoking cessation in a population of individuals with a diagnosis of head and neck cancer. The aims of this study were twofold: (1) assess the prevalence of smoking cessation in those with a previous diagnosis of head and neck cancer, (2) analyze the determinants of smoking alongside area-based measures of socioeconomic status.

Methods: This was a cross-sectional study. We administered a self-reported nicotine dependence package to participants between the ages of 20-90 with a previous mucosal head and neck cancer diagnosis and with a history of tobacco use. Using the Canadian Marginalization (CAN-Marg) Index tool based on 2006 Canada Census data we compared the degree of marginalization to the smoking status. For those individuals who were currently smoking, nicotine dependence and readiness to quit were assessed. A summative score of marginalization was compared to smoking status of individuals.

Results: The results from this study indicate that the summative level of marginalization developed from the combined factors of residential instability, material deprivation, ethnic concentration and dependency may be important factors in smoking cessation.
\end{abstract}

Conclusions: This analysis of determinants of smoking alongside area-based measures of socioeconomic status may implicate the need for targeted population-based smoking cessation interventions.

Keywords: Smoking, Tobacco, Cancer, Addiction

\section{Introduction}

There has been a recent interest in studying how contexts are related to the individual characteristics of geographic areas [1]. Area context has been shown to have significant relevance when it comes to forming policy. Furthermore, it becomes of particular importance when analyzing the determinants of health and mortality rates. It has been suggested that interventions to improve health should focus on efforts to improve neighbourhoods in socially disadvantaged areas $[1,2]$. Individuals

\footnotetext{
* Correspondence: gracemargaretscott@gmail.com

1 Department of Rural and Northern Health, Laurentian University, Sudbury, Canada

Full list of author information is available at the end of the article
}

living in these areas have higher rates of mortality and morbidity independent of individual-level characteristics. This study explores the barriers to smoking cessation $\mathrm{SC}$ ) in individuals with a head and neck cancer diagnosis through an area-based perspective.

Smoking remains the number one cause of preventable death in Canada [3]. In cancer patients and survivors, the evidence is sufficient to infer a causal relationship between cigarette smoking and increased all-cause mortality and cancer-specific mortality [4]. Furthermore, in the field of head and neck cancer, the most important risk factors are tobacco and alcohol [5-10]. It is also well documented that $\mathrm{SC}$ after diagnosis improves prognostic outcomes [9]. Correspondingly, smoking cessation interventions in the

(c) The Author(s). 2019 Open Access This article is distributed under the terms of the Creative Commons Attribution 4.0 International License (http://creativecommons.org/licenses/by/4.0/), which permits unrestricted use, distribution, and reproduction in any medium, provided you give appropriate credit to the original author(s) and the source, provide a link to the Creative Commons license, and indicate if changes were made. The Creative Commons Public Domain Dedication waiver (http://creativecommons.org/publicdomain/zero/1.0/) applies to the data made available in this article, unless otherwise stated. 
Table 1 Demographic Information

\begin{tabular}{|c|c|c|c|}
\hline \multirow[t]{2}{*}{ Variable } & & \multicolumn{2}{|l|}{ Total n (\%) } \\
\hline & & Current Smokers & Reformed Smokers \\
\hline Number of Participants & & $28(24.8)$ & $85(75.2)$ \\
\hline Men & & $18(64.3)$ & $66(77.6)$ \\
\hline Women & & $10(35.7)$ & $19(22.4)$ \\
\hline Age & Mean - & 67.95 & 63.29 \\
\hline \multicolumn{4}{|l|}{ Cancer Site } \\
\hline Oral Cavity & & $15(53.6)$ & $32(37.6)$ \\
\hline Larynx & & $5(17.9)$ & $33(38.8)$ \\
\hline Oropharynx & & $7(25)$ & $18(21.2)$ \\
\hline Other & & $1(3.6)$ & $2(2.4)$ \\
\hline \multicolumn{4}{|l|}{ Treatment Type } \\
\hline Surgery & & 15 (53.6) & $62(72.9)$ \\
\hline Radiation & & $21(75)$ & $55(64.7)$ \\
\hline Chemotherapy & & $14(50)$ & $25(29.4)$ \\
\hline \multicolumn{4}{|l|}{ Marital Status } \\
\hline Married & & $13(46.4)$ & $52(61.2)$ \\
\hline Divorced & & $1(3.6)$ & $11(12.9)$ \\
\hline Separated & & $0(0)$ & $1(1.2)$ \\
\hline Widowed & & $6(21.4)$ & $4(4.7)$ \\
\hline Common-Law & & $1(3.6)$ & $10(11.8)$ \\
\hline Single & & $5(17.9)$ & $6(7.1)$ \\
\hline Undisclosed & & $2(7.1)$ & $1(1.2)$ \\
\hline \multicolumn{4}{|l|}{ Occupational Status } \\
\hline Full Time & & $3(10.7)$ & $15(17.6)$ \\
\hline Part Time & & $1(3.6)$ & $2(2.4)$ \\
\hline Retired & & $12(42.9)$ & $57(67)$ \\
\hline Disability & & $10(35.7)$ & $8(9.4)$ \\
\hline Undisclosed & & $2(7.1)$ & $3(3.5)$ \\
\hline
\end{tabular}

perioperative period after a diagnosis of head and neck cancer have been shown to represent a unique opportunity for success [11]. Patients with head and neck cancer who continue to smoke after diagnosis and treatment are more likely to experience tumor recurrence and second primary malignancies. Previous research found that smoking during radiotherapy or chemoradiotherapy for head and neck cancer significantly reduced survival; however, patients who quit 12 weeks before treatment did not have significantly reduced survival [12]. A recent analysis from a randomized phase III trial of radiotherapy or chemoradiotherapy found that current smoking during treatment significantly decreased disease-specific and overall survival in patients with head and neck cancer, and that smoking substantially worsened the otherwise favorable prognosis of human papillomavirus-driven head and neck cancer $[13,14]$. Beyond radiotherapy and chemotherapy, smokers compared with nonsmokers and former smokers compared with those who never smoked have more postoperative healing complications. Additionally, perioperative smoking cessation reduces surgical site infections [15]. Although the diagnosis of a tobacco related malignancy clearly represents a strong catalyst for SC, a sizable subgroup of patients continue to smoke [16].

Due to the importance of cessation, and the various barriers to success in this endeavour, we aimed to study some of these aspects with respect to socioeconomic variation. The main aim of this study was to analyze the determinants of smoking alongside area-based measures of socioeconomic status.

\section{Methods}

This was a cross-sectional study and included consecutive English speaking head and neck cancer patients between the ages of 20-90. Participants were recruited from four different sites in Ontario between 2013 and 2017. This included two northern Ontario sites (Sudbury and Sault Ste. Marie) and two southern Ontario sites (London and Hamilton). We included all of those with a mucosal head and neck cancer diagnosis (excluding melanoma) with a history of tobacco use. Tobacco use was identified by a retrospective review of clinic charts/notes.

\section{Measurement instruments}

We administered a demographic questionnaire and for those participants who were currently smoking we administered the CAMH readiness ruler [17] and the Fagerstom test [18] for nicotine dependence. All questionnaires were completed over the telephone.

\section{CAN-Marg}

In order to address our second objective and analyze the determinants of smoking alongside area-based measures of socioeconomic status we used the Canadian Marginalization Index [19]. CAN-Marg is a census-based, empirically derived and theoretically informed tool designed to reflect a broader conceptualization of Canadian marginalization. The index has demonstrated marked stability across time and geographic area. Each of the four dimensions show strong and significant associations with selected health and behavioural issues, and these associations differ depending on which of the dimensions of marginalization is examined. The four dimensions of the tool are residential instability, material deprivation, ethnic concentration and dependency. Each group contains a fifth of the geographic units. A summative marginalization score can be calculated as the mean quintile value of each of these 4 subdimensions.

\section{Statistical analysis}

Alongside descriptive statistics, a Mann-Whitney test was conducted to assess differences between groups. 


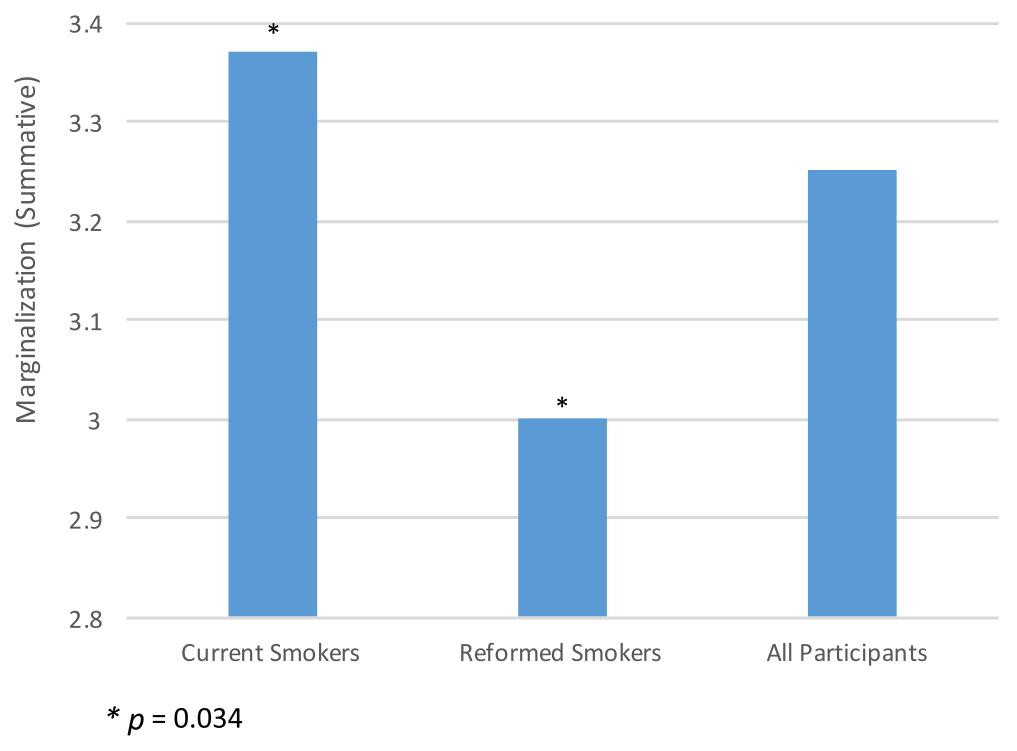

Fig. 1 Summative marginalization scores across Ontario

Significance was defined at $p<0.05$. All data were analyzed using SPSS 22.0 for Windows (IBM Corp., 2013).

\section{Results}

In total, 278 individuals were invited to participate in this study. Complete questionnaires were received from 113 participates (40.6\% response rate). This included 28 (24.8\%) current smokers and 85 (71.2\%) previous smokers. The total number of participants recruited from each site was as follows: Sault Ste. Marie $(n=34$ $(30.1 \%))$, Sudbury $(n=50 \quad(44.2 \%))$, London $(n=28$ $(24.8 \%))$, and Hamilton $(\mathrm{n}=5(4.4 \%))$. A complete breakdown of demographics by smoking status can be found in Table 1. Of note, the 3 participants with 'other' cancer sites included two pyriform sinus (hypopharyx) and a nasal septal lesion.

A Mann-Whitney U Test was conducted for summative marginalization scores and compared current smokers to reformed smokers. This test revealed a significant difference in summative marginalization scores of current smokers and reformed smokers as shown in Fig. 1.

Using Cohen's measure of effect sizes, we see a small effect in both of these cases as denoted by an r-value of .19 for summative marginalization.

The results from the participants that continued to smoke yielded a mean score of 4.3 (out of 10) on the Fagerstom test for nicotine dependence. A higher score on this test indicates a great level of dependence. A score of 4.3 indicates a moderate level of dependence. The readiness ruler gauged the level of importance, confidence and readiness to quit smoking as a score out of 10 . On this test, the smokers had mean importance, confidence and readiness scores of 6.3, 5.1 , and 4.9 respectively.

Using geographic information system mapping, we were able to plot the summative marginalization scores from all of the dissemination areas of the participants. A higher summative marginalization score indicates a greater level of marginalization in that area. The scale ranges from 1 to 5 , with 1 being the lowest level of marginalization and 5 the highest. Figure 2 depicts a visual representation of respondents by geographic area. The areas on the map that remain blank represent those dissemination areas not represented by participants in this study. Additionally, no participants in this study received a summative score of 1 (indicating the lowest level of marginalization).

\section{Discussion}

If we are to construct effective policy responses to health inequalities, especially at the local level, then it is essential that these be informed by an understanding of the potential importance of the geographic factors [2]. Amongst other factors, these contextual effects would appear to impact patients' intention to quit smoking, as indicated by our results. Participants that continue to smoke tended to live in more marginalized communities as compared to those that have successfully quit smoking.

The present study found that $24.8 \%(n=28)$ of participants continued to smoke after a diagnosis of head and neck cancer. A similar study examined lifestyle behaviours in a heterogeneous group of adult cancer survivors and found that since cancer diagnosis, $46 \%$ of smokers quit smoking and $47 \%$ improved their dietary habits 


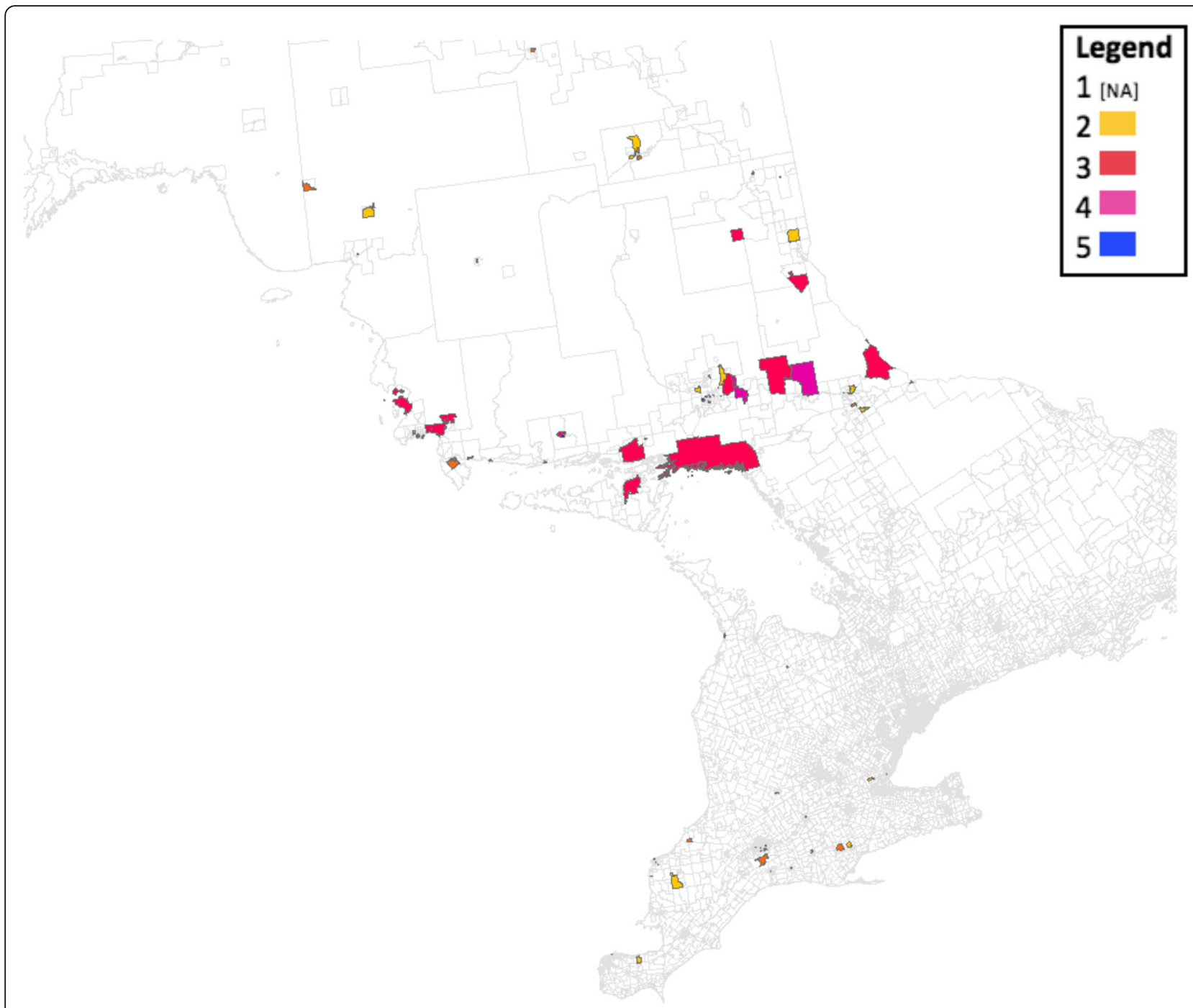

Fig. 2 Summative marginalization across Ontario

[20]. They also found that these adult cancer survivors who changed their lifestyle behaviors varied greatly and specifically related this to demographic variables [20]. The higher quit rate in our study may highlight the unique factors associated with a head and neck cancer diagnosis as compared to other cancer types. Though other cancer sites are associated with tobacco abuse, smoking unequivocally causes head and neck cancer [21]. The implicit tie between smoking and head and neck cancer indicates the need for targeted smoking cessation interventions [22]. Although a majority of health care providers acknowledge that smoking cessation is within their scope of practice, many are unsure of their specific role [23].

There are several limitations to acknowledge in this study. As a cross-sectional study, the results are reflective of one distinctive point in time and this may limit the generalizability of the study findings. All participants included in this study had a history of tobacco use. Because of this, there is no way of knowing whether non-smokers would have displayed a similar pattern of marginalization. We are also unable to extract baseline smoking rates for these geographical regions and are unable to compare the rate of smoking in the study population to baseline rates by geographic area. Additionally, geographic area based on residential postal code was used as a surrogate marker for marginalization in this population. As an area-based measure of geographic marginalization, the marginalization scores identified for each participant may not reflect the actual level of individual marginalization. Futhermore, this was a voluntary, self-reporting study. In this case, the results are subject to both selection and response bias. Individuals may have been excluded from being invited to participate in this study based on their response to tobacco use questioning. 


\section{Conclusion}

Though SC may be important to individuals who continue to smoke after a cancer diagnosis, they may not feel ready or confident in their ability to quit. Summative level of marginalization developed from the combined factors of residential instability, material deprivation, ethnic influences and dependency may be a critical factor in SC. Our goal was to further develop an understanding of the moderating factors behind one's decision to continue to smoke after a diagnosis of head and neck cancer and whether the social determinants of health such as neighbourhood socioeconomic deprivation play a role. Despite having the same access to regional cancer centres, oncologists, SC education and a multidisciplinary cancer team as per Cancer Care Ontario's (provincial governmental advisor on cancer care) rules and regulations, there remain intrinsic differences in smoking behaviours based on area based socio-economic status. This may suggest a need for specific targeted population-based SC interventions.

\section{Acknowledgements}

The authors acknowledge Tomasz Mrozewski and his development of the GIS maps.

\section{Authors' contributions}

DM was the senior author on this paper, he was responsible for overseeing all aspects of the project including data collection, data analysis, and manuscript preparation. DM, CS, MG, KF, and DS were the otolaryngologists involved in this research study and each contributed patients to this study. Each otolaryngologist also contributed to data analysis and manuscript preparation. CB was involved with research ethics board approval, data collection, data analysis, and manuscript preparation. Finally, GS was the first author on this paper and contributed to conceptualization of experimental design, data collection, data analysis and manuscript preparation. All authors read and approved the final manuscript.

\section{Funding}

This study was supported by the Sault Ste. Marie Academic Medical Association.

\section{Availability of data and materials}

The datasets generated and/or analysed during the current study are not publicly available due to confidentialty, but are available from the corresponding author on reasonable request.

\section{Ethics approval and consent to participate}

Ethics approval received from the Sault Area Hospital and Group Health Centre Joint Research Ethics Board, Western University, and McMaster University.

\section{Consent for publication}

Information on publication intentions was included in the letter of information to participants; consent forms attained.

\section{Competing interests}

The authors declare that they have no competing interests.

\section{Author details}

${ }^{1}$ Department of Rural and Northern Health, Laurentian University, Sudbury, Canada. ${ }^{2}$ Department of Otolaryngology-Head \& Neck Surgery, University of Ottawa, Ottawa, Canada. ${ }^{3}$ Department of Otolaryngology-Head \& Neck Surgery, Western University, London, Canada. ${ }^{4}$ Otolaryngology-Head \& Neck Surgery Division, McMaster University-Dept. of Surgery, Hamilton, Canada.
${ }^{5}$ Department of Otolaryngology-Head \& Neck Surgery, Northern Ontario School of Medicine, Sudbury, Canada.

Received: 10 December 2018 Accepted: 25 September 2019

Published online: 24 October 2019

\section{References}

1. Martikainen P, Kauppinen TM, Valkonen T. Effects of the characteristics of neighbourhoods and the characteristics of people on cause specific mortality: a register based follow up study of 252000 men. J Epidemiol Community Health. 2003;57(3):210-7.

2. Curtis S, Rees $\mathrm{Jl}$. Is there a place for geography in the analysis of health inequality? Sociology of health \& illness. 1998;20:645-72

3. Baliunas D, Patra J, Rehm J, et al. Smoking-attributable mortality and expected years of life lost in Canada 2002: conclusions for prevention and policy. Chronic Diseases in Canada. 2007:27:154-62

4. US Department of Health and Human Services. (2014). The health consequences of smoking-50 years of progress: a report of the surgeon general. Atlanta, GA: US Department of Health and Human Services, Centers for Disease Control and Prevention, National Center for Chronic Disease Prevention and Health Promotion, Office on Smoking and Health, 17.

5. Decker J, Goldstein JC. Risk factors in head and neck cancer. N Engl J Med. 1982;306:1151-5.

6. Falk RT, Pickle LW, Brown LM, et al. Effect of smoking and alcohol consumption on laryngeal cancer risk in coastal Texas. Cancer Res. 1989;49:4024-9.

7. Jacobs CD. Etiologic considerations for head and neck squamous cancers. In: Jacobs C, editor. Carcinomas of the head and neck: evaluation and management. Boston: Kluwer Academic; 1990. p. 265-82.

8. Nam J, McLaughlin JK, Blot WJ. Cigarette smoking, alcohol, and nasopharyngeal carcinoma: a case-control study among U.S. whites. J Natl Cancer Inst. 1992:84:619-22.

9. Vokes EE, Weichselbaum RR, Lippman SM, et al. Head and neck cancer. N Engl J Med. 1993;328(3):184-94.

10. Winn DM, Blot WJ, McLaughlin JK, et al. Mouthwash use and oral conditions in the risk of oral and pharyngeal cancer. Cancer Res. 1991;51:3044-7.

11. Nayan S, Gupta MK, Strychowsky JE, Sommer DD. Smoking cessation interventions and cessation rates in the oncology population: an updated systematic review and meta-analysis. Otolaryngol Head Neck Surg. 2013;149(2):200-11.

12. Browman GP, Wong G, Hodson I, et al. Influence of cigarette smoking on the efficacy of radiation therapy in head and neck cancer. $N$ Engl J Med. 1993;328:159-63.

13. Gillison ML, Zhang Q, Jordan R, et al. Tobacco smoking and increased risk of death and progression for patients with p16-positive and p16-negative oropharyngeal cancer. J Clin Oncol. 2012;30:2102-11.

14. Toll BA, Brandon TH, Gritz ER, et al. Assessing tobacco use by cancer patients and facilitating cessation: an American Association for Cancer Research policy statement. Clin Cancer Res. 2013;19(8):1941-8.

15. Sørensen LT. Wound healing and infection in surgery: the clinical impact of smoking and smoking cessation: a systematic review and meta-analysis. Arch Surg. 2012;147(4):373-83.

16. Ostroff JS, Jacobsen PB, Moadel AB, et al. Prevalence and predictors of continued tobacco use after treatment of patients with head and neck cancer. Cancer. 1995;75(2):569-76.

17. Centre for Addiction and Mental Health. 2006. Retrieved from http://www. healthunit.org/professionals/ruralnursing/Readiness_Ruler.pdf.

18. Heatherton TF, Kozlowski LT, Frecker RC, et al. The Fagerström test for nicotine dependence: a revision of the Fagerstrom tolerance questionnaire. Br J Addict. 1991;86(9):1119-27.

19. Matheson FI, Dunn JR, Smith KL, et al. Development of the Canadian marginalization index: a new tool for the study of inequality. Canadian Journal of Public Health/Revue Canadienne de Sante'e Publique, 2012;S12-S16.

20. Blanchard CM, Denniston MM, Baker F, et al. Do adults change their lifestyle behaviors after a cancer diagnosis? Am J Health Behav. 2003;27:246-56.

21. Leemans $\mathrm{CR}$, Braakhuis BJ, Brakenhoff RH. The molecular biology of head and neck cancer. Nat Rev Cancer. 2011;11(1):9-22. 
22. Chan Y, Irish JC, Wood SJ, Sommer DD, Brown DH, Gullane PJ, O'Sullivan B, Lockwood GA. Smoking cessation in patients diagnosed with head and neck cancer. J Otolaryngol 2004 1;33(2).

23. Scott GM, Alsaffar H, Doyle PC, et al. Smoking cessation practice: do we practice it well? Do we know it well? Jacobs Journal of Addiction and Therapy. 2015;2(3):020

\section{Publisher's Note}

Springer Nature remains neutral with regard to jurisdictional claims in published maps and institutional affiliations.

Ready to submit your research? Choose BMC and benefit from:

- fast, convenient online submission

- thorough peer review by experienced researchers in your field

- rapid publication on acceptance

- support for research data, including large and complex data types

- gold Open Access which fosters wider collaboration and increased citations

- maximum visibility for your research: over $100 \mathrm{M}$ website views per year

At $B M C$, research is always in progress. 